\title{
PENGARUH PENDIDIKAN KESEHATAN TERHADAP MOTIVASI MENGONTROL KADAR GULA DARAH PADA PASIEN DM TIPE II
}

\author{
Dian Sukma Dewi Arimbi ${ }^{1}$ Lita $^{2}$, Rani Lisa Indra ${ }^{3}$ \\ ${ }^{1,2,3}$ Program Studi Keperawatan STIKes Hang Tuah Pekanbaru \\ Email: diansukmadewiarimbi@gmail.com
}

\begin{abstract}
ABSTRAK
Motivasi dari setiap individu berkaitan dengan pengetahuan yang dimiliki masing-masing pasien. Tingkat motivasi pasien yang rendah dapat dipengaruhi oleh pengetahuan yang rendah terutama tidak didapatkannya pendidikan kesehatan secara baik, sehingga kontrol gula darah pada pasien DM tipe II tidak dapat berjalan dengan baik. Tujuan dari penelitian ini adalah untuk mengetahui pengaruh pendidikan kesehatan terhadap motivasi mengontrol kadar gula darah pada pasien diabetes melitus tipe II. Jenis penelitian yang digunakan adalah pre-eksperiment dengan desain one group pre and post test. Penelitian dilaksanakan di Wilayah Kerja Puskesmas Rejosari. Dengan sampel yang digunakan sebanyak 35 pasien DM menggunakan teknik penelitian Purposive Sampling. Instrumen yang digunakan kuesioner demografi responden dan kuesioner motivasi yang di uji menggunakan dependent t-test. Hasil menunjukkan bahwa pengaruh pendidikan kesehatan terhadap motivasi dalam mengontrol kadar gula darah pada pasien DM tipe II diperoleh p 0.000. Kesimpulan yaitu ada pengaruh antara pendidikan kesehatan terhadap motivasi pasien DM tipe II dalam mengontrol kadar gula darah di wilayah kerja puskesmas Rejosari. Dari hasil penelitian diharapkan kepada pihak puskesmas khususnya puskesma Rejosari untuk dapat meningkatkan kegiatan baik berupa kegiatan penyuluhan dan pendidikan kesehatan untuk meningkatkan motivasi pasien DM tipe II mengontrol kadar gula darah.
\end{abstract}

Kata kunci : Diabetes Melitus, Motivasi, Pendidikan Kesehatan.

\begin{abstract}
The motivation of each patient is related to her knowledge. The low level of patient motivation can be affected by low knowledge especially not getting good helath education that blood sugar control in type II diabetes mellitus patients cannot run well. The purpose of this study was to determine the effect of helath education on the motivation to control blood sugar levels in patients with type II diabetes mellitus. This study was a pre experiment study used one group pretest-posttest design. With sample was 35 type II diabetes mellitus patients using purposive sampling techniques. The study was conducted at public health center Rejosari. The instruments used were questionnaire demographic characteristics of respondents and motivational questionnaires tested using the dependent $t$-test. The results of the dependent statistic test shower that the effect of health education on motivation in controlling blood sugar levels in patient with type II diabetes mellitus at public health center Rejosari Obtained p-value $=0.000$. The conclusion is that there is an influence between health education ant motivation of type II diabetes mellitus patients in controlling blood sugar levels in the public health center Rejosari. Based on the result of the study was expected to the members of the public health center, especially the public health center in Rejosari to be able to improve their activity health education and guidance to improve the motivation of the patient type II to control the blood sugar.
\end{abstract}

Keywords : Diabetes Mellitus, Motivation, Health Education.

\section{PENDAHULUAN}

DM adalah salah satu penyakit kronik yang disebabkan karena pankreas tidak menghasilkan insulin dengan baik, atau dikarenakan tubuh tidak mampu secara baik menggunakan insulin yang dihasilkan, dengan glukosa darah puasa $\geq 126 \mathrm{mg} / \mathrm{dl}$ dan kadar gula darah sewaktu $\geq 200 \mathrm{mg} / \mathrm{dl} \quad$ (WHO, 2016; ADA, 2016). 
Berdasarkan data International Diabetes Federation (IDF), Indonesia termasuk peringkat ke-6 di dunia dalam prevalensi pasien DM pada tahun 2017, setelah Tiongkok, India, Amerika Serikat, Brazil, dan Meksiko dengan jumlah pasien DM sebanyak 10,3 juta pasien, dan diperkirakan akan mengalami peningkatan menjadi 16,2 juta orang pasien pada tahun 2040. Berdasarkan Riset Kesehatan Dasar (Riskesdes) pada tahun 2018, DM di Provinsi Riau merupakan tertinggi ke-3 di Indonesia setelah DKI Jakarta dan Kalimantan Timur, dengan proporsi $2,0 \%$. Terdapat berbagai jenis DM, namun yang prevalensinya paling banyak adalah DM tipe II yaitu sekitar $30-50 \%$ sedangkan prevalensi DM gestasional sebesar $10-25 \%$ dan selebihnya DM tipe I (WHO, 2016).

Berdasarkan data Dinas Kesehatan Kota Pekanbaru (2017), angka kejadian DM tipe II merupakan peringkat ke 3 dari 10 penyakit terbesar di Kota Pekanbaru sebanyak 19093 kasus dengan jumlah kunjungan paling banyak dari 20 Puskesmas yang ada di Kota Pekanbaru berada di wilayah kerja Puskesmas Rejosari Kecamatan Tenayan Raya dengan jumlah 2.428 kunjungan pada tahun 2017 (Dinkes, 2017).

DM tipe II merupakan tipe yang sering terjadi karena gaya hidup yang tidak sehat. Pasien DM tipe II akan berisiko mengalami komplikasi makrovaskuler dan mikrovaskuler. Menurut hasil penelitian Wardani (2014), terjadinya komplikasi ini sebagai akibat dari karena pasien DM tidak mengetahui penyakit yang dideritanya atau mengetahui penyakit yang dideritanya tetapi pasien DM memandang penyakit yang dideritanya merupakan penyakit yang dapat langsung sembuh dalam satu kali pemeriksaan. Rutin melakukan kunjungan berobat (kontrol) ke pelayanan kesehatan adalah salah satu pencegahan komplikasi.

Kontrol gula darah sangat penting untuk pasien diabetes melitus sebagai penentu penanganan medis yang tepat, sehingga dapat mencegah komplikasi dan membantu pasien untuk menyesuaikan atau mengatur gaya hidup (Perkeni, 2011; Shrivastava, \& Ramasamy, 2013). Kadar glukosa darah dinyatakan tidak terkontrol apabila kadar glukosa puasa $>7,0 \mathrm{mmol} / \mathrm{dl}$ atau $126 \mathrm{mg} / \mathrm{dl}$ (Rachmawati, 2015). Standar pemeriksaan di pelayanan kesehatan idealnya 3 bulan sekali setelah kunjungan pertama, yang meliputi pemeriksaan kadar glukosa darah puasa, 2 jam setelah makan, dan pemeriksaan HbA1C (Mahendra, 2008). Tetapi untuk seberapa sering cek gula darah, setiap masing-masing individu berbeda tergantung dari pengobatan yang diberikan dan saran dari petugas kesehatan atau dokter (Tandra, 2013).

Pengendalian DM secara efektif diperlukan untuk mencegah atau meminimkan komplikasi akibat dari lamanya penyakit DM (Kementerian Kesehatan RI, 2014). Penatalaksanaan DM terdiri dari 4 pilar yaitu edukasi, diet, olahraga dan intervensi farmakologis, dan edukasi merupakan yang utama menjadi dasar membangun pengetahuan (IDF, 2013). Edukasi diabetes merupakan pendidikan untuk meningkatkan pengetahuan dan keterampilan pasien DM. Peran perawat sangat penting sebagai edukator untuk menginformasikan kepada pasien pentingnya kontrol gula darah. Hal ini dapat mengubah perilaku pasien sehingga persentase kadar gula darah pasien yang buruk dapat diminimalkan (Asmadi, 2008). Perilaku kesehatan adalah tindakan yang berkaitan dengan upaya pencegahan untuk menghindari masalah kesehatan (preventif), serta 
perilaku dalam mengupayakan, mempertahankan dan meningkatkan kesehatan (promotif). Perilaku pasien DM dalam mengontrol kadar gula darah dipengaruhi oleh pengetahuan, kepercayaan dan sikap positif, tersedianya sarana dan prasarana yang diperlukan, serta motivasi (Notoatmodjo, 2014).

Motivasi adalah dorongan dari dalam diri individu maupun lingkungan untuk bertindak atau melakukan sesuatu. Oleh karena itu motivasi berhubungan dengan dorongan dan tujuan untuk melakukan manajemen perawatan diri (Notoatmodjo, 2010). Motivasi merupakan salah satu faktor mendukung perubahan perilaku kearah yang lebih baik. Pasien dengan motivasi yang tinggi memiliki tingkat komitmen yang tinggi dalam melakukan kontrol kadar gula darah, sedangkan pasien dengan motivasi yang rendah juga akan memiliki tingkat komitmen yang rendah pula dalam melakukan kontrol kadar gula darah. Menurut Given (2002) dalam Tombokan (2015) mengatakan bahwa tingkat kepatuhan berobat salah satunya dipengaruhi oleh Motivasi. Salah satu faktor yang dapat mempengaruhi motivasi adalah pengetahuan. Perawat dapat terlibat untuk memberikan pendidikan kesehatan untuk meningkatkan pengetahuan dalam upaya meningkatkan motivasi pasien diabetes melakukan kontrol kadar gula darah. Laporan penelitian Aini (2011) yang dilakukan di Rumkital Dr. Ramelan Surabaya pada 15 pasien tentang pengetahuan kepatuhan berobat pasien penyakit DM adalah 100\%, 47\% (7 orang) sikap sedang,53\% (8 orang) sikap baik, 6\% (1 orang) praktik kurang, 40\% (6 orang) praktik sedang dan baik $54 \%$ (8 orang). Walaupun tingkat pengetahuan pasien sudah baik (pengetahuan baik mungkin disebabkan karena sudah sering mendapatkan penyuluhan dari rumah sakit), namun praktik yang baik hanya 54\%. Ketidakpatuhan mengontrol glukosa darah dan kontrol ke pelayanan kesehatan masih menjadi masalah yang penting dalam pengelolaan diabetes melitus. Selain faktor medis, status sosial ekonomi, tingkat pendidikan dan pengetahuan yang rendah serta depresi yang dialami pasien DM, sangat berkaitan dengan kepatuhan yang rendah dan tingkat morbiditas yang tinggi pada pasien diabetes melitus (Delameter, 2006; Kocurek, 2009).

Studi pendahuluan yang dilakukan pada tanggal 26 januari 2019 di Kelurahan Rejosari Kecamatan Tenayan Raya, hasil wawancara terhadap 8 orang pasien DM, 5 orang diantara mereka mengaku enggan ke puskesmas atau ke pelayanan kesehatan untuk mengontrol kadar gula darah, karena belum adanya keluhan terkait dengan gejala penyakit DM, takut dan tidak percaya dengan penanganan medis, malas untuk pergi berobat karena sibuk dengan pekerjaan rutin dan tanpa gejala pasien merasa sembuh. Berdasarkan fenomena diatas peneliti tertarik untuk melakukan penelitian mengenai " Pengaruh pendidikan kesehatan terhadap motivasi mengontrol kadar gula darah pada pasien DM tipe II di Wilayah Kerja Puskesmas Rejosari”. Tujuan dari penelitian ini adalah untuk mengetahui pengaruh pendidikan kesehatan terhadap motivasi mengontrol kadar gula darah pada pasien DM tipe II.

\section{METODELOGI PENELITIAN}

Jenis penelitian ini adalah penelitian pre-eksperiment design dengan rancangan penelitian one group pretestposttest design. Populasi yang dimaksudkan dalam penelitian ini 
adalah jumlah pasien diabetes melitus yang berkunjung di Puskesmas Rejosari pada tahun 2018 yang berjumlah 701 pasien. Sampel pada penelitain ini adalah pasien diabetes melitus tipe II yang tidak rutin melakukan kontrol kadar gula darah dan memiliki data jelas di Puskesmas Rejosari dan dapat dihubungi. Pengambilan sampel dalam penelitian ini menggunakan Purposive Sampling dengan alat pengumpulan data menggunakan lembar kuesioner motivasi.

\section{HASIL PENELITIAN}

Hasil penelitian yang dilakukan dari bulan Mei dampai bulan Juli 2019 pada 35 responden pasien diabetes melitus di wilayah kerja puskesmas Rejosari, dengan data yang diperoleh sebagai berikut.

\section{A. Karakteristik Responden}

Tabel 1. Distribusi frekuensi umur, jenis kelamin, pekerjaan, pendidikan, dan lama menderita DM.

\begin{tabular}{clcc}
\hline NO & $\begin{array}{c}\text { Karakteristik } \\
\text { Responden }\end{array}$ & $\mathrm{N}$ & $\%$ \\
\hline 1 & $\quad$ Umur & & \\
& $50-60$ & 28 & 80.1 \\
& $61-67$ & 7 & 20.2 \\
\hline 2 & Jenis Kelamin & & \\
& Laki-laki & 9 & 25.7 \\
& Perempuan & 26 & 74.3 \\
\hline 3 & $\quad$ Pekerjaan & & \\
& PNS & 12 & 34.3 \\
& Swasta & 2 & 5.7 \\
& IRT & 19 & 54.3 \\
& Lain-lain & 2 & 5.7 \\
\hline 4 & Pendidikan & & \\
& Tidak sekolah & 3 & 8.6 \\
& SD & 5 & 14.3 \\
& SMP & 7 & 20.0 \\
& SMA & 11 & 31.4 \\
& Perguruan Tinggi & 9 & 25.7 \\
\hline 5 & Lama menderita & & \\
& $\quad$ DM & & \\
& 1 Tahun & 17 & 48.6
\end{tabular}

$\begin{array}{lcc}2 \text { Tahun } & 7 & 20.0 \\ 3 \text { Tahun } & 11 & 31.4\end{array}$

Berdasarkan hasil analisa pada tabel 1 dapat disimpulkan bahwa sebagian besar pasien diabetes melitus berusia 50-60 tahun yaitu berjumlah 28 orang (80.1\%). Mayoritas pasien adalah perempuan dengan jumlah 26 orang (74.3\%). Berdasarkan karakteristik pendidikan terakhir sebagian besar pasien adalah SMA dengan jumlah 11 orang (31.4\%). Status pekerjaan mayoritas pasien adalah IRT dengan jumlah 19 orang (54.3\%). Sebagian besar pasien menderita DM sudah 1 tahun dengan julah 17 orang (48.6\%).

\section{B. Uji Normalitas Shapiro Wilk Sebelum dan Sesudah diberikan Pendidikan Kesehatan}

Tabel 2 Uji Normalitas Shapiro wilk motivasi sebelum dan sesudah pemberian pendidikan kesehatan di wilayah kerja puskesmas Rejosari

\begin{tabular}{cc}
\hline Variabel & P value $>0.05$ \\
\hline Pre-test & 0.204 \\
Post-test & 0.112 \\
\hline
\end{tabular}

Berdasarkan uji shapiro wilk pada tabel diatas dapat dilihat bahwa $\mathrm{p}$ value $>0.05$ sehingga dapat disimpulkan data dikatakan normal.

\section{Uji Analisis Statistik Perbandingan Motivasi sebelum dan sesudah diberikan Pendidikan Kesehatan dengan Uji Dependen Simple T test}

Tabel 3 Uji analisis statistik perbandingan motivasi sebelum dan sesudah pemberian pendidikan kesehatan dengan menggunakan uji dependen simple T-test di wilayah kerja puskesmas Rejosari 


\begin{tabular}{llll}
\hline Variabel & $\begin{array}{l}\text { Mean } \\
\text { dif }\end{array}$ & $\begin{array}{l}\text { Std } \\
\text { error } \\
\text { mean dif }\end{array}$ & $\begin{array}{l}\mathrm{P} \\
\text { value } \\
<0.05\end{array}$ \\
\hline $\begin{array}{l}\text { PreTest }- \\
\text { PostTest }\end{array}$ & - & 0.81310 & 0.000 \\
\hline
\end{tabular}

Hasil analisa diatas, menunjukkan bahwa setelah dilakukan pendidikan kesehatan pada 35 responden menunjukkan motivasi responden sesudah diberikan pendidikan kesehatan lebih tinggi dari motivasi responden sebelum diberikan pendidikan kesehatan dengan rata-rata -5.08571 dan hasil uji statistik p value 0.000 ( $\mathrm{p}$ value $<0.05$ ) maka dapat disimpulkan Ho di tolak dan $\mathrm{Ha}$ diterima yaitu adanya pengaruh pendidikan kesehatan terhadap motivasi mengontrol kadar gula darah pasien diabetes melitus di wilayah kerja puskesmas Rejosari.

\section{PEMBAHASAN}

\section{A. Karakteristik Responden \\ 1. Umur}

Hasil penelitian tentang pengaruh pendidikan kesehatan terhadap motivasi mengontrol kadar gula darah pada pasien DM tipe II di wilayah kerja puskesmas rejosari didapatkan bahwa pasien yang mengalami diabetes melitus adalah pasien yang rata-rata usia minimum 50 tahun dan usia maksimum 67 tahun dengan rata-rata usia responden 56.51 tahun. Hasil penelitian ini didukung oleh Isnaini dan Ratnasari (2018) yang menyatakan bahwa faktor usia sangat berpengaruh dengan $\mathrm{p}=0,010$ dan orang yang berusia 50 tahun keatas lebih rentan terserang diabetes melitus namun tidak menutup kemungkinan juga bahwa orang yang berusia dibawah 50 tahun terbebas dari diabetes melitus, dan semakin meningkat umur seseoran semakin besar kejadian DM tipe II.
Usia memiliki kaitan erat dengan kenaikan jumlah gula darah, semakin bertambah usia maka risiko untuk mengalami DM tipe II semakin tinggi. Proses menua dapat mengakibatkan perubahan sistem anatomi, fisiologi dan biokimia tubuh yang salah satu dampaknya adalah peningkatan resistensi insulin (Smeltzer \& Bare, 2014).

\section{Jenis kelamin}

Jenis kelamin perempuan lebih banyak yang mengalami diabetes melitus tipe II dibandingkan laki-laki pada penelitian ini. Penelitian lain juga mengatakan hal yang sama. Hasil penelitian ini didukung oleh susanti (2019) yang dilakukan dari 89 orang penderita DM tipe II ditemukan 68 orang (76.4\%) adalah wanita. Akhsyari dan rahayuningsih (2017) dalam penelitian mendapatkan hasil bahwa dari jumlah sampel 99 orang, 54,5\% adalah wanita. Jumlah wanita yang menderita DM dibandingkan jumlah laki-laki lebih banyak. Hal ini karena hormon esterogen hormon yang dimiliki wanita yang apabila terjadi peningkatan dan penurunan dapat mempengaruhi kadar glukosa darah (Smeltzer \& Bare, 2014).

\section{Pekerjaan}

Pada penelitian ini pekerjaan pasien yang mengalami diabetes melitus tipe II adalah sebagai Ibu Rumah Tangga (IRT). Hasil penelitian ini didukung oleh isnaini, dan ratnasari (2018) yang menyatakan pekerjaan berhubungan dengan aktivitas fisik dan aktivitas olahraga. Ibu rumah tangga melakukakn beberapa aktivitas di rumah seperti mencuci, memasak dan membersihkan rumah serta banyak aktivitas yang tidak dapat dideskripsikan. Aktivitas fisik akan berpengaruh terhadap peningkatan insulin sehingga kadar gula dalam darah akan berkurang. Jika insulin tidak 
mencukupi untuk mengubah glukosa menjadi energi maka akan timbul DM. pekerjaan sebagai ibu rumah tangga termasuk dalam aktivitas ringan. Sejalan dengan penelitian yang dilakukan Maharani, Suryono dan Ardiyanto (2018), bahwa orang yang aktivitas fisiknya buruk (54,8\%) memiliki risiko lebih besar menderita DM tipe II dibandingan dengan orang yang memiliki aktivitas baik.

\section{Pendidikan}

Berdasarkan hasil penelitian ini diperoleh tingkat pendidikan pasien yang mengalami diabetes melitus tipe II terbanyak yaitu SMA. Hasil penelitian ini didukung oleh Rahma (2018), menyatakan bahwa terdapat pengaruh faktor risiko tingkat pendidikan terhadap risiko terkena penyakit diabetes melitus tipe II, dan yang memiliki peluang yang paling besar terhadap penyakit diabetes melitus adalah tingkat pendidikan SMA atau yang sederajat (76.7\%). Tingkat pendidikan memiliki pengaruh terhadap kejadian penyakit diabetes melitus tipe II. Orang yang tingkat pendidikannya tinggi biasanya akan memiliki banyak pengetahuan tentang kesehatan. Dengan adanya pengetahuan tersebut orang akan memiliki kesadaran dalam menjaga kesehatannya. Hal ini sesuai dengan literature yang menyatakan rendahnya tingkat pendidikan dan pengetahuan merupakan salah satu penyebab tingginya angka kasus suatu penyakit. Pengetahuan bisa diperoleh melalui promosi kesehatan salah satunya pendidikan kesehatan (Notoatmodjo,2010).

\section{Lama menderita DM}

Hasil penelitian tentang pengaruh pendidikan kesehatan terhadap motivasi mengontrol kadar gula darah pada pasien DM tipe II di wilayah kerja puskesmas Rejosari didapatkan bahwa pasien yang mengalami diabetes melitus adalah pasien dengan rata-rata lama menderita DM minimum 1 tahun dan maksimum 3 tahun dengan rata-rata lama menderita DM responden 1.82 tahun. Penderita sering terdeteksi atau mulai menyadari DM adalah 7 tahun sebelum diagnosis ditegakkan sehingga angka morbiditas dan mortalitas dini terjadi pada kasus yang tidak terdeteksi, dan penderita baru menyadari bahwa kadar gula darah sudah mengalami peningkatan.

Hasil penelitian ini sejalan dengan Aisyah (2018) tentang karakteristik lama menderita DM dengan kejadian DM tertinggi 1-5 tahun. Dimana lama menderita DM ini dapat mempengaruhi depresi pada pasien seperti pasien mengalami kebosanan dan merasa putus asa,salah satunya dalam menjalankan kontrol ke dokter. Hasil penelitian Prasestiyo (2017) menyatakan bahwa lama menderita DM berhubungan dengan kualitas hidup karena kualitas hidup yang baik akan menjadikan seseorang tetap menjalankan aktifitas hidup sehari-hari secara normal baik segi fisik, mental dan sosial.

\section{Pengaruh Pendidikan Kesehatan Terhadap Motivasi Mengontrol Kadar Gula Darah}

Pendidikan kesehatan, efektif dalam meningkatkan motivasi pasien diabetes melitus dalam mengontrol kadar gula darah dengan pvalue 0.000. Apabila motivasi pasien baik dalam mengontrol kadar gula darah, maka gula darah dalam tubuh pasien akan terkontrol yang akan mencegah terjadinya komplikasi sehingga kesejahteraan pasien akan meningkat. Sesuai dengan penelitian Pratama (2016) dimana terdapat pengaruh signifikan antara pendidikan kesehatan terhadap 
pengetahuan dan sikap pada pasien DM dalam pengelolaan diet DM sebelum dan setelah diberikan perlakuan pendidikan kesehatan di puskesmas Boyolali dengan nilai $p=0.000<0,05$. Penelitian ini juga didukung oleh penelitian Mutoharoh (2017) tentang pengaruh pendidikan kesehatan terhadap pengetahuan tentang penyakit diabetes melitus pada penderita diabetes melitus tipe 2 di Ngadiwarno Sukorejo dengan pvalue $=0.001$.

Pendidikan kesehatan salah satu upaya yang baik untuk meningkatkan pengetahuan. Pengetahuan merupakan seluruh kemampuan individu untuk berpikir dan bertindak secara terarah dan efektif, sehingga orang yang mempunyai pengetahuan tinggi akan mudah menyerap informasi, saran dan nasihat. Meningkatnya pengetahuan penderita diabetes melitus tentang penyakitnya akan mampu meningkatkan motivasi penderita diabetes melitus dalam mengontrol kadar gula darah. Motivasi penderita diabetes melitus dalam mengontrol kadar gula darah dipengaruhi oleh motivasi instrinsik yang datangnya dari dalam diri individu itu sendiri seperti keinginan patuh dan teratur dalam berobat atau terapi medis dan keinginan untuk meningkatkan pengetahuan tentang penyakitnya dan motivasi ekstrinsik yang datangnya dari luar diri sendiri seperti dukungan keluarga, teman dekta, dukungan ekonomi dan dukungan petugas kesehatan.

Jika pengetahuan seseorang berkurang akan sangat berpengaruh terhadap motivasi dari individu. Karena pendidikan kesehatan sangat mempengaruhi tingkat pengetahuan pada individu terhadap perilaku kehidupan sehari-hari dan disertai tingkat pengetahuan yang baik pada setiap individu inilah yang akan meningkatkan motivasi untuk upaya pencegahan penyakit. Hasil tersebut juga didukung oleh penelitian Prabawati (2017) tentang pengaruh pendidikan kesehatan dengan media Booklet terhadap motivasi latihan fisik pasien DM di wilayah kerja Puskesma Purwokerto Utara dengan pvalue 0.000 . Pendidikan kesehatan merupakan faktor penting dalam menunjang kesehatan masyarakat dan sering dilaksanakan di pelayanan kesehatan oleh perawat sebagai edukator. Keberhasilan penatalaksanaan diabetes salah satunya disebabkan oleh pendidikan kesehatan karena dari hal tersebut pasien diabetes dapat mengetahui bagaimana mengatur pola hidup sehat walaupun menyandang diabetes.

Sasaran pendidikan kesehatan dalam penelitian ini adalah pendidikan kesehatan pada tingkat kuratif, yang mana sasaran pada tingkat ini adalah, para penderita penyakit (pasien), terutama untuk para penderita penyakit kronik salah satunya diabetes melitus yang tujuannya adalah agar kelompok ini mampu mencegah penyakit tersebut dan tidak menjadi lebih parah (Notoatmodjo, 2010). Penelitian ini juga menggunakan metode pendidikan kesehatan dengan metode individual (perorangan). Metode pendidikan individual (perorangan) merupakan metode yang digunakan untuk membina perilaku baru, atau seseorang yang telah mulai tertarik kepada suatu perubahan perilaku atau inovasi. Dasar digunakannya karena setiap orang mempunyai masalah atau alasan yang berbeda-beda sehubungan dengan penerimaan atau perilaku baru tersebut (fitriani, 2011). Pendidikan kesehatan dengan metode individual sudah banyak digunakan untuk meningkatkan pengetahuan namun masih jarang digunakan untuk meningkatkan 
motivasi terutama motivasi mengontrol kadar gula darah.

Motivasi merupakan suatu usaha yang dilakukan untuk mempengaruhi tingkah laku seseorang agar tergerak untuk mencapai hasil atau tujuan tertentu. Menurut teori motivasi erat kaitannya dengan kebutuhan salah satunya kebutuhan fisiologis. Kebutuhan fisiologis berkaitan langsung dengan hidup manusia. Jika kebutuhan ini tidak terpenuhi maka individu tidak akan tergerak untuk memenuhi kebutuhan yang lain (Nursalam 2012). Salah satu kebutuhan fisiologis bagi pasien diabetes yaitu kondisi fisik yang optimal dan terbebas dari ancaman komplikasi diabetes. Hal tersebut dalam kontens ini dapat diatasi dengan mengontrol kadar gula darah.

Kebutuhan terutama kebutuhan fisiologis mempengaruhi motivasi seseorang. Pendidikan kesehatan untuk meningkatkan motivasi mengontrol kadar gula darah pada pasien DM tipe II dengan cara menanamkan kesadaran pada individu bahwa kebutuhan fisiologis mereka yaitu kondisi fisik yang optimal dan kadar gula darah yang terkontrol meskipun mengalami diabetes. Kesadaran tersebutlah yang akan menjadi energi untuk meningkatkan motivasi menjadi lebih tinggi. Penelitian Risti (2017) didapatkan ada hubungan motivasi diri dan pengetahuan gizi terhadap kepatuhan diet DM pada pasien diabetes melitus tipe II rawat jalan di RSUD Karanganyar dengan nilai $\mathrm{p}=0.002<$ alpha 0.05 .

Berdasarkan data penelitian, responden mempunyai motivasi mengontrol kadar gula darah rendah mayoritas karena responden merasa takut untuk mengontrol kadar gula darah di puskesmas atau rumah sakit, karena sibuk dengan pekerjaan, tidak ada yang menemani, belum mengetahui betul manfaat dan prinsip mengontrol kadar gula darah yang baik dan benar untuk pasien DM, dan lebih yakin dengan pengobatan tradisional. Pada pendidikan kesehatan yang diberikan peneliti, responden menerima informasi bahwa mengontrol kadar gula darah merupakan salah satu 4 pilar dalam penatalaksanaan diabetes melitus. Mengontrol kadar gula darah secara teratur dapat mencegah terjadi nya komplikasi.

\section{KESIMPULAN}

Berdasarkan hasil penelitian, maka dapat diambil kesimpulan bahwa responden yang merupakan pasien diabetes didominasi oleh responden berjenis kelamin perempuan, berusia rata-rata 50-67 tahun, berpendidikan terakhir mayoritas SMA, dan pekerjaan Ibu Rumah Tangga. Rata-rata motivasi responden sebelum pendidikan kesehatan yaitu 31.40 dan setelah diberikan pendidikan kesehatan yaitu 36.48. Motivasi responden sesudah diberikan pendidikan kesehatan lebih tinggi dibandingkan motivasi sebelum diberikan pendidikan kesehatan, sehingga dapat disimpulkan ada pengaruh pendidikan kesehatan terhadap motivasi mengontrol kadar gula darah pada pasien DM tipe II di wilayah kerja puskesmas Rejosari.

\section{SARAN}

\section{Bagi Institusi pendidikan}

Bagi institusi pendidikan khususnya keperawatan, diharapkan penelitian ini dijadikan sumber informasi dan diterapkan untuk sebagai kegiatan pengabdian masyarakat. Selanjutnya penelitian ini juga dijadikan evidence based untuk masa yang akan datang. 
2. Bagi Wilayah Kerja Puskesmas Rejosari

Diharapkan setelah dilakukan penelitian ini bagi petugas puskesmas dapat meningkatkan kegiatan baik berupa penyuluhan dan pendidikan kesehatan untuk meningkatkan motivasi pasien DM tipe II mengontrol kadar gula darah.

\section{Bagi Ilmu Keperawatan}

Diharapkan terutama bagi perawat komunitas mampu terlibat langsung dalam melakukan kegiatan penyuluhan dan pendidikan kesehatan serta kegiatan lain di masyarakat agar masyarakat mempunyai tingkat pengetahuan yang cukup baik tentang diabetes melitus sehingga masyarakat bisa menerapkan prilaku hidup yang lebih baik salah satunya mengontrol kadar gula darah.

\section{Bagi Masyarakat}

Bagi masyarakat khususnya pasien diabetes melitus untuk lebih meningkatkan motivasi untuk mengikuti penyuluhan di puskesmas terdekat atau mencari informasi tentang diabetes melitus agar pengetahuan masyarakat meningkat sehingga motivasi untuk mengontrolkadar gula darah juga meningkat.

\section{Bagi peneliti selanjutnya}

Diharapkan bagi peneliti selanjutnya untuk melakukan penelitian yang lebih mendalam yaitu dengan mengambil sampel masyarakat diabetes melitus dan tidak hanya menghubungkan pengaruh pendidikan kesehatan tentang diabetes melitus terhadap motivasi mengontrol kadar gula darah saja.

\section{DAFTAR PUSTAKA}

Akhsyari, F. Z. (2016). Karakteristik pasien diabetes mellitus di RSUD dr. Soehadi Pritonegoro Sragen. Skripsi. PSIK. Universitas Muhammadiyah : Surakarta.

Ardiyanto, B. F., Suryon, I., \& Maharani, N. E. (2018). Hungungan Obesitas dan aktivitas fisik dengan kejadian diabetes melitus tipe 2. Jurnal manajemen informasi dan administrasi kesejatan.1(01),40-48.

Asmadi. (2008). Konsep dasar keperawatan. Edisi 1. EGC: Jakarta.

American Diabetes Association. (2016). Standar of Medical Care in Diabetes 2016: Classification and diagnosis of diabetes. Diabetes care. $39: 13-22$.

Delamater, A. M . (2006). Improving Patient Adherence., 24(2), 71-77.

International Diabetes Federation. (2013). Diabetes Atlas Sicth Edition. Desember 24. 2018 Http://www.idf.org/elibrary/epidemiologyresearch/diabetes-atlas/19-atlas6th-edition.html

(2015). Diabetes Atlas Seventh Edition. Desember 252018 Http://www.oedg.at/pdf/1606_atlas 2015 UK.pdf.

Isnaeni, F. N., \& Risti, K. N. (2017). Hubungan motivasi diri dan pengetahuan gizi terhadap kepatuhan diet DM pada pasien diabetes melitus tipe II rawat jalan di RSUD karanganyar. Jurnal kesehatan. 10(02), 94-103.

Kartika, I. I. (2017). Dasar-dasar riset 
keperawatan dan pengolahan data statistik. Jakarta: KDT.

Kocurek B. (2009). Promoting medicationadherence in Older Adults Through Early Diagnosis of Neurocognitive Disorders. 22: 8084.

Mahendra B. (2008). Care Your Self: Diabetes Melitus. Jakarta : Penebar Plus.

Mutoharoh. (2017). Pengaruh pendidikan kesehatan terhadap tingkat pengetahuan tentang penyakit diabetes mellitus pada penderita diabetes mellitus tipe 2 di desa ngadiwarno sukorejo. Skripsi. Fakultas Kedokteran dan Ilmu Kesehatan : Jakarta.

Notoadmojo, S. (2010). Ilmu perilaku Kesehatan. Jakarta: Rineka Cipta. . (2014). Ilmu Perilaku Kesehatan. Jakarta : Rineka Cipta.

Perkeni. (2011). Pengelolaan dan Pencegahan Diabetes Melitus Tipe 2 di Indonesia. Jakarta : Perkeni.

Prabawati, S. (2017). Pengaruh pendidikan kesehatan dengan media booklet terhadap motivasi latihan fisik pasien DM di wilayah kerja puskesmas purwokerto utara. Skripsi. Fakultas Ilmu-Ilmu Kesehatan : Purwokerto.

Prasestiyo H. (2017). Analisa Hubungan Faktor Lama Menderita Dan Komplikasi Dengan Kualitas Hidup Pasien Diabetes Melitus Di Rumah Sakit PKU Muhammadiya Bantul. Skripsi. Fakultas Ilmu Keperawatan : Yogyakarta.

Pratama, P. A. (2016). Pengaruh pendidikan kesehatan terhadap pengetahuan dan sikap pasien tentang pengelolaan diet diabetes melitus di puskesmas boyolali. Skripsi. Fakultas Ilmu Kesehatan :

Rahma, F., Almasdy, D., Yosmar, R. (2018). Survei risiko penyakit diabetes mellitus terhadap masyarakat kota padang. Jurnal sains farmasi \& klinis. 5(2), 134141.

Rambiharilal,S.,\& Shrivastava,P.S. S. and J. R. (2013). Role of self-care in management of diabetes mellitus, $12(1), \quad 1$. https://doi.org/10.1186/2251-658112-14.

Ratnasari.,\& Isnaini, N. (2018). Faktro Risiko Mempengaruhi Kejadian Diabetes Melitus Tioe Dua. Jurnal Keperawatan, 1(14), 59-68.

Ricart, W., \& Real, J. M. F. (2006). No

Sabrian, F., Aisyah, S., Hasneli, Y. (2018). Hubungan antara dukungan keluarga dengan kontrol gula darah dan olahraga pada penderita diabetes melitus. 5(2), 211-221.

Smeltzer, S. C. \& Bare, B.G. (2014). Keperawatan Medikal Bedah Brunnert \& Suddarth. Jakarta : EGC.

Tandra H. (2008). Segala Sesuatu yang Harus Kamu Ketahui Tentang Diabetes. Jakarta: PT Gramedia Pustaka Utama.

Vera Tobokan A.J.Rattu Ch.R.Tilaar. (2000). Faktor-faktor yang Berhubungan dengan Kepatuhan Berobat Pasien Diabetes Melitus pada Praktek Dokter Keluarga di Kota Tomohon.260-269. 
Wardani, K. W., \& Isfandiari, M. A. (2014). Hubungan dukungan keluarga dan pengendalian kadar gula darah dengan gejala komplikasi mikrovaskuler. Jurnal Epidemiologi, 2, 1-12.

World Health Organization. (2016). Global Report On Diabetes. Geneva: WHO Library Cataloguis in Publication Data. 